\title{
Management of acute coronary syndrome in special subgroups: female, older, diabetic and Indigenous patients
}

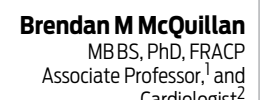
Cardiologist $^{2}$

Peter L Thompson MD, FRACP, FACC Clinical Professor,' and Cardiologist and Head, Heart Research Institute ${ }^{2}$

1 School of Medicine and Pharmacology, University of Western Australia, Perth, WA.

2 Sir Charles Gairdner Hospital, Perth, WA.

peterlthompson@ health.wa.gov.au

doi: 10.5694/mjal4.01248
W hile guidelines for the management of acute coronary syndrome (ACS) for the average patient are well defined, their application to special groups is less clear. Some groups have been underrepresented or formally excluded from the clinical trials that constitute the evidence base that guides therapy, and some have special needs that have not been studied in clinical trials. As a result, these subgroups present clinical challenges for which there is weaker evidence to define appropriate management.

This article will assess the special needs of women, older people, patients with diabetes, and Aboriginal and Torres Strait Islander Australians.

\section{Women}

Cardiovascular disease remains the leading cause of death in women, and far exceeds deaths from cancer at all ages. Despite the popular perception that heart attack is far more common in men than women, this is true only in younger age groups. Across the full spectrum of age, women account for a large proportion of patients with ACS, comprising up to $45 \%$ of patients in some series ${ }^{1}$ and $40 \%$ in a comprehensive snapshot of admissions to coronary care units in Australia and New Zealand in 2012. ${ }^{2}$

There is considerable evidence that the pattern of coronary disease and ACS is different in men and women. ${ }^{3,4}$ Women tend to have less obstructive coronary artery disease and a higher prevalence of microvascular coronary dysfunction, ${ }^{5}$ leading to the suggestion that the term ischaemic heart disease may be more appropriate for women than coronary artery disease. ${ }^{6}$

While most women presenting with an ACS will experience typical anginal symptoms, women are less likely to report chest pain or discomfort compared with men. They are more likely to report associated symptoms including dyspnoea, nausea and fatigue. ${ }^{7}$ These differences may be partly explained by the higher average age at ACS presentation among women, with older patients of both sexes less likely to report chest pain. ${ }^{7}$ There is a higher prevalence of stress or takotsubo cardiomyopathy among women, usually in the absence of obstructive coronary disease. ${ }^{8}$ There are also some differences in the reference range and pattern of troponin elevation between the sexes. ${ }^{9}$ Overall, however, the diagnostic and prognostic performance of troponins is similar in men and women. ${ }^{10}$ These differences complicate the diagnosis of ACS in women, and may contribute to delays or deficiency in the delivery of guideline-indicated therapies.

The outcomes after an ACS are worse for women than men. ${ }^{11}$ The most likely explanation is that women have their heart attacks about a decade later in age than men. After detailed multivariate analysis of age and other prognostic factors, being female is not an independent

\begin{abstract}
Summary
While the evidence base for management of acute coronary syndrome (ACS) is extensive, some subgroups have been underrepresented or excluded from relevant clinical trials.

These subgroups - such as women, older people, diabetic patients and Indigenous Australians - present clinical challenges for which there is limited evidence to guide optimal therapy.

Women may have a different pattern of presentation, with potential for delays in diagnosis and worse outcomes in ST-elevation myocardial infarction, but there is no evidence that treatments affect them differently from men.

Older people suffer from a high-risk, low-treatment paradox. This may be due to under-appreciation of the benefits of treatments for older people, or to good clinical judgement in avoiding harm from worsening age-related comorbidities.

Patients with diabetes have a high risk of ACS and suffer worse outcomes. Moderate glycaemic control with close monitoring and avoidance of hypoglycaemia are recommended. Coronary artery bypass grafting is preferred to percutaneous coronary intervention for patients with diabetes and multivessel disease, although the latter is reasonable in single-vessel disease.

Indigenous patients have a high prevalence of coronary disease, with more frequent coronary events at a young age, a heavy load of risk factors and poor outcomes after ACS. The complex sociocultural barriers to treatment are yet to be addressed adequately.
\end{abstract}

risk factor for non-ST-elevation ACS (NSTEACS), but it is for ST-elevation myocardial infarction (STEMI) ${ }^{12}$ This disparity in STEMI is particularly evident in younger women ( $<55$ years old), who have a higher risk of death and recurrent events compared with similarly aged men. ${ }^{13,14}$

Concerns have been expressed that women may not receive the same benefit from invasive management as men experiencing an NSTEACS. Individually, the trials comparing conservative with invasive management were each underpowered to demonstrate a benefit in women. Reports from meta-analyses of the trials give conflicting results. Trials to 2008 showed a clear benefit in women at higher risk, ${ }^{15}$ but a more recent meta-analysis including the data from the OASIS 5 trial failed to demonstrate any benefit for women from an early invasive approach. ${ }^{16}$ It is clear that women receive invasive management less frequently than men, probably because of higher rates of comorbidity rather than a treatment bias, ${ }^{17}$ but do not fare any worse solely because of a lower rate of intervention. ${ }^{18}$

Women are less likely to receive guideline-indicated pharmacotherapies after ACS. The clinical trials for guiding pharmacotherapy after an ACS episode have tended to include far fewer women than men. As a result, the 
evidence base to guide therapy in women is less robust than for men. ${ }^{19}$ Despite this, there is no clear evidence that the usual post-ACS medications are less efficacious in women than in men. The available evidence shows equivalent efficacy for the post-ACS use of aspirin, ${ }^{20}$ clopidogrel $^{21}$ and ticagrelor, ${ }^{22}$ as well as the short- and long-term use of $\beta$-blockers, ${ }^{23}$ statin therapy ${ }^{24}$ and angiotensin-converting enzyme inhibitors ${ }^{25}$ after myocardial infarction. Due to generally lower body weight and estimated glomerular filtration rates, especially among older women, caution is required to avoid excess dosing of antithrombotic therapy. Meta-analysis of the available clinical trials of hormone replacement therapy has shown no benefit, but no adverse effect of hormone replacement therapy after ACS. ${ }^{26}$

\section{Older people}

Older people comprise a large proportion of patients with ACS. In the United States-wide CRUSADE study, patients aged 75 years and older comprised $35 \%$ of all ACS patients. ${ }^{27}$ The risk of a poor outcome after ACS rises with age, and each of the widely used scoring systems shows a major influence of age. In the Thrombolysis in Myocardial Infarction (TIMI) score for STEMI patients, an age of 75 years or older had an adjusted odds ratio of 2.7 for predicting 30-day mortality. ${ }^{28}$ In the Global Registry of Acute Coronary Events (GRACE) score for patients with NSTEACS, each decade of increasing age was associated with an adjusted odds ratio of 1.7 for predicting 30-day mortality, with those aged 75 years having an eightfold higher risk of death at 30 days compared with a 40-year-old. ${ }^{29,30}$ In 8557 patients from Australia and New Zealand enrolled in the LIPID Study, the rate of death or myocardial infarction over a mean of 6 years was $19.6 \%$ in patients aged 70 years and older compared with $11.2 \%$ in patients younger than 60 years, with a hazard ratio of 1.89 (95\% CI, 1.60-2.23). ${ }^{31}$

Because of their higher absolute risk of adverse cardiovascular events after ACS, patients aged 75 years and older have potentially more to gain from appropriate therapies if they offer similar risk reduction across all ages. Despite this, there is a well recognised paradox that older patients who are at highest risk often receive less active treatment. The tolerability, safety and adverse event profile of these therapies must also be carefully considered for older patients. Clinical trials have enrolled lower proportions of older patients, with lower rates of comorbidities especially renal impairment, stroke and congestive heart failure, than are present in community series. ${ }^{27}$ The proportion of patients presenting with atypical symptoms or non-diagnostic electrocardiogram changes increases with age, which may result in delays in the diagnosis of ACS and institution of appropriate therapies. ${ }^{32}$ Patients' preferences and their perception of risks associated with invasive management must also be taken into account.

Although concerns regarding bleeding risks and vascular complications including stroke may explain lower rates of invasive strategies among older patients with ACS, similar patterns are observed for pharmacotherapy. Although each of the evidence-based post-ACS treatments has been shown to be effective for older patients, ${ }^{33}$ there may be a reluctance to treat this group. Some of the reluctance for intervention and pharmacotherapy in older patients no doubt reflects sensible clinical judgement, as there may be increased risks with some medications with age.

The relative benefit of aspirin does not appear to be affected by age. Compared with younger patients, people aged 65 years and older had a greater absolute reduction in vascular end points and lower death rate with aspirin use after ACS. ${ }^{34}$ For inhibitors of adenosine diphosphatedependent platelet aggregation, when added to aspirin in the management of ACS, there is divergence in the risk-benefit profile for older patients. Clopidogrel offers similar absolute risk but lower relative risk reduction when given to patients older than 65 years compared with younger patients, although in both groups clopidogrel is more effective than placebo. ${ }^{35-37}$ Patients aged 75 years and older and those with a body weight below $60 \mathrm{~kg}$ demonstrated no net clinical benefit from prasugrel in the TRITON-TIMI 38 study of ACS patients with scheduled percutaneous coronary intervention (PCI). ${ }^{38}$ Those with prior stroke or transient ischaemic attack, which are more prevalent among older patients, had net harm with prasugrel. Ticagrelor was superior to clopidogrel in the overall PLATO trial, and has been shown to be of similar efficacy in reducing subsequent cardiovascular events among patients aged 75 years and older compared with younger patients. ${ }^{39}$ Bleeding rates were similar to those with clopidogrel in patients 75 years and older and not significantly different to rates in those younger than 75 years included in PLATO. Dyspnoea and ventricular pauses were more common with ticagrelor, but at similar rates regardless of age.

Statins for secondary prevention of cardiovascular events have consistently demonstrated benefit compared with placebo, with most trials finding greater absolute risk reduction among patients aged 65 years and older compared with those younger than 65 years. ${ }^{40}$ These findings have been extended in the PROSPER ${ }^{41}$ and Heart Protection $^{42}$ studies, which included larger numbers of patients aged 75-80 years, with similar event reduction in each of the age groups. Meta-analysis of statin trials examining the benefit of more versus less aggressive lowering of low-density lipoprotein cholesterol levels for secondary prevention of cardiovascular events has shown similar efficacy in those aged older than 65 years compared with patients aged 65 years and under. ${ }^{43}$ For ACS trials, efficacy has been shown with high-dose atorvastatin compared with lower-dose atorvastatin ${ }^{44}$ or pravastatin, ${ }^{45}$ without evidence of differential treatment benefits due to age. Statin therapy may have more side effects in older patients, particularly in higher doses, and closer surveillance is warranted. ${ }^{46}$

Older patients also have a higher likelihood of renal dysfunction that is not necessarily identified from serum creatinine levels, ${ }^{47}$ and some studies estimate that significant renal dysfunction is present in up to $35 \%$ of people over the age of 70 years. ${ }^{48}$ The likelihood of worsening renal dysfunction from use of contrast medium can be a factor in decision making for older patients who are being considered for invasive therapy. ${ }^{49}$ Many cardiovascular 
drugs are cleared by renal mechanisms, and dosing considerations should be observed..$^{50}$ Renal dysfunction can also be a significant factor in increasing the risk of bleeding with anticoagulants, particularly with low-molecularweight heparins, which are cleared via the renal route. ${ }^{51,52}$ Registry data show that excessive doses of antithrombotic agents are frequently given to older patients. ${ }^{50}$

Routine invasive therapy, which has a well recognised benefit in reducing myocardial infarction and recurrent angina compared with a selective invasive strategy, ${ }^{53}$ can have an even greater benefit in older patients at high risk. The TACTICS-TIMI 18 trial compared the impact of invasive and conservative strategies in younger (aged $65-75$ years) and older (aged over 75 years) patients. The early invasive strategy conferred an absolute reduction in end points of $10.8 \%$ in younger patients, and $21.6 \%$ in older patients $(P=0.016) .{ }^{54}$ Despite this evidence of greater benefit, international ${ }^{55}$ and Australian ${ }^{56,57}$ studies have shown that older patients at higher risk routinely receive less invasive management than younger patients.

Explanations for this paradox in the delivery of invasive therapy vary, but there are valid clinician concerns about comorbidities, interaction with concomitant medications and increased fragility, which are more likely explanations than an "ageist" bias. Concerns about a higher risk of bleeding in older patients may restrict the use of invasive therapies, as bleeding has been shown to be an independent predictor of a poor outcome after an ACS event. ${ }^{58}$

\section{People with diabetes}

Diabetes is an important risk factor for cardiovascular disease, with a threefold increased risk of ACS, and an increased risk of post-infarct heart failure, recurrent ischaemia and death. ${ }^{59}$ In Australia, $25 \%$ of patients who present with ACS have diabetes. ${ }^{2}$ Compared with patients without diabetes, patients whose ACS occurs in the setting of diabetes tend to have more extensive coronary artery disease $\mathrm{e}^{60}$ and angioscopic evidence of more unstable disease with ulcerated plaques and intracoronary thrombi. ${ }^{61}$ There is evidence of disordered cardiac function in diabetes which may be independent of myocardial ischaemia, ${ }^{62}$ and includes a high prevalence of diastolic ventricular dysfunction. ${ }^{63}$

Patients with poor glycaemic control during their ACS have a worse outcome. Even modest elevations of plasma glucose levels in patients without known diabetes, previously referred to as "stress hyperglycaemia", is related to increased mortality. ${ }^{64}$ While intensive medical therapy to achieve strict glycaemic control in patients with diabetes has been shown to reduce the risk of microvascular complications and some cardiovascular disease events in long-term follow-up, ${ }^{65,66}$ there have been inconsistent results in the context of ACS. While small early open-label clinical studies appeared to have favourable results, ${ }^{67}$ subsequent larger blinded randomised controlled trials failed to confirm any clear benefit of insulin- or sulfonylurea-based therapy to tightly control glucose levels. ${ }^{68}$ The use of fixed-rate glucose, insulin and potassium (GIK) infusions has been studied in several trials, including the CREATE-ECLA study in patients with STEMI, ${ }^{69}$ with prespecified analyses combined with the GIK component of the OASIS- 6 trial. ${ }^{70}$ These trials included more than 20000 patients, 5000 of whom had diabetes. There was no beneficial effect of GIK infusion on outcomes, with possible harm resulting from excess fluid load, although the early excess in mortality became neutral at 30 days. When prehospital GIK therapy was administered to patients with suspected ACS, the IMMEDIATE trial demonstrated no initial benefit ${ }^{71}$ or improvement in overall outcomes at 1 year. $^{72}$

The role of intensive insulin therapy in ACS patients has been further informed by studies of strict glycaemic control in critically ill patients. The Australian NICE-SUGAR trial in multicentre intensive care settings demonstrated increased mortality with intensive glycaemic control and emphasised the serious adverse consequences of hypoglycaemia in these patients. ${ }^{73}$ There was a lower mortality rate with a blood glucose target of below $10.0 \mathrm{mmol} / \mathrm{L}$ $(<180 \mathrm{mg} / \mathrm{dL})$ than with a target of $4.4-6.1 \mathrm{mmol} / \mathrm{L}$ (81-108 mg/dL). ${ }^{73}$ Current guidelines have recognised the differences between long-term benefits of intensive glycaemic control in younger patients with more recent diabetes onset, and the lack of benefit or potential harm among the critically ill or older patients with longstanding diabetes at the time of ACS. ${ }^{74}$ The focus should be on active management of hyperglycaemia, with blood glucose levels below $11.0 \mathrm{mmol} / \mathrm{L}$ while avoiding hypoglycaemia. Dose-adjusted insulin infusions with regular monitoring of blood glucose levels should be considered, but routine administration of insulin and glucose with or without potassium is not recommended unless there is a clinical indication.

Trials of most guideline-indicated pharmacotherapy for patients with ACS and diabetes have demonstrated similar or greater risk reduction than for patients without diabetes. Dual antiplatelet therapy with aspirin and clopidogrel has demonstrated similar benefits for patients with diabetes compared with overall trial participants, although people with diabetes face a higher residual risk of recurrent events, possibly reflecting more persistent platelet activation. Prasugrel and ticagrelor offer more rapid and complete platelet inhibition and superior net clinical benefit to clopidogrel in studies of patients with diabetes and ACS, with similar overall bleeding rates in patients with diabetes. ${ }^{75,76}$ Inhibitors of platelet glycoprotein IIb/IIIa receptors (including abciximab, eptifibatide and tirofiban) may have a role in high-risk ACS patients, including people with diabetes who are undergoing PCI.77

Statins have been shown to offer consistent benefit for secondary prevention of cardiovascular events among patients with diabetes, compared with placebo. The Cholesterol Treatment Trialists' analysis included more than 1000 participants with type 1 diabetes, mainly middle-aged people with prior cardiovascular disease, and found a similar risk reduction to that seen with type 2 diabetes. ${ }^{78}$ Meta-analysis of trials examining more intensive versus moderate statin therapy have confirmed similar benefits for participants without diabetes. ${ }^{79}$ For patients with diabetes and ACS, high-dose atorvastatin was superior to pravastatin, with a greater absolute risk reduction than was observed in patients without diabetes. It was noted that only $38 \%$ of participants with diabetes achieved the intended goals of a low-density lipoprotein 
cholesterol level below $1.81 \mathrm{mmol} / \mathrm{L}(<70 \mathrm{mg} / \mathrm{dL})$ and a high-sensitivity C-reactive protein level below $2 \mathrm{mg} / \mathrm{L} .{ }^{80}$ Dyslipidaemia is common among people with diabetes, and has been recognised as an independent predictor of adverse outcomes. Trials to date have demonstrated the primary role of statins, but there is some evidence of benefit for fibrates in patients with diabetes and dyslipidaemia for long-term secondary prevention. ${ }^{81,82}$

For ACS, patients with diabetes compared with the overall population obtain similar or greater reduction in mortality and recurrent myocardial infarction with an early invasive strategy and revascularisation when possible. ${ }^{83}$ The choice of revascularisation approach is complicated by superior results with coronary artery bypass graft (CABG) surgery compared with $\mathrm{PCI}$ in patients with diabetes and multivessel disease, even when newgeneration drug-eluting stents are used. ${ }^{84,85}$ These trials, however, did not typically include patients with ACS. The recommendations of the American College of Cardiology Foundation/American Heart Association guidelines are that for patients with diabetes, single-vessel disease in the setting of NSTEACS ${ }^{86}$ or acute coronary occlusion of the infarct-related vessel in STEMI ${ }^{87}$ should be managed with PCI, but CABG is preferred for the management of multivessel disease.

\section{Aboriginal and Torres Strait Islander people}

Coronary heart disease is twice as prevalent in the Australian Indigenous population as the non-Indigenous population. ${ }^{88}$ This population has a high prevalence of cardiovascular risk factors ${ }^{89}$ and established atherosclerosis. ${ }^{90}$ A detailed 2006 report by the Australian Institute of Health and Welfare showed that Indigenous Australians had three times the rate of major coronary events and more than twice the inhospital coronary heart disease death rate of other Australians. ${ }^{91}$ The high incidence affects remote-dwelling ${ }^{92}$ and urban-dwelling Aboriginal Australians. ${ }^{93,94}$ The disparities are even more striking in younger age groups. In a Western Australian study, the incidence of coronary events in the 25-29-years age group was 27 times (men) and 35 times (women) higher than in non-Aboriginal participants of the same age, decreasing to two to three times the non-Indigenous rates at 70-74 years. ${ }^{95}$ A higher frequency of comorbid conditions, primarily diabetes, adversely affects short- as well as long-term survival. ${ }^{96}$

There are complex sociocultural barriers to delivery of optimal care for Indigenous patients with ACS. ${ }^{97}$ Lower rates of treatment have been reported. The Australian Institute of Health and Welfare study of $2006^{88}$ reported a $40 \%$ lower rate of being investigated by angiography, a $40 \%$ lower rate of coronary angioplasty or stent procedures and a $20 \%$ lower rate of CABG surgery. These apparently lower rates of coronary revascularisation in Aboriginal patients disappeared when patients were matched for age, sex and comorbidity. After this adjustment, the rates and type of intervention (including PCI and CABG surgery) during an ACS event were identical. ${ }^{98}$ Similarly, the adjusted rates of evidence-based prescribing for post-hospital secondary prevention were similar in Aboriginal and non-Aboriginal patients. ${ }^{99}$
Some subgroups of patients experiencing ACS require special attention in assessment and management. While women, older people, people with diabetes and Indigenous patients may be underrepresented in clinical trials, there is evidence that most guideline-based therapies offer similar benefits in these subgroups. Barriers to routine prescription of effective post-ACS therapies in these patients need to be overcome.

Competing interests: Peter Thompson has received research funding from AstraZeneca, Boehringer Ingelheim, Pfizer, Bristol-Myers Squibb and Amgen and advisory board fees from AstraZeneca and Pfizer.

Provenance: Commissioned; externally peer reviewed.

1 Goldberg RJ, Yarzebski J, Lessard D, Gore JM. A two-decades (1975 to 1995) long experience in the incidence, in-hospital and long-term case-fatality rates of acute myocardial infarction: a community-wide perspective. J Am Coll Cardiol 1999; 33: 1533-1539.

2 Chew DP, French J, Briffa TG, et al. Acute coronary syndrome care across Australia and New Zealand: the SNAPSHOT ACS study. Med J Aust 2013; 199: 185-191.

3 Hochman JS, McCabe CH, Stone PH, et al. Outcome and profile of women and men presenting with acute coronary syndromes: a report from TIMI IIIB. TIMI Investigators. Thrombolysis in Myocardial Infarction. J Am Coll Cardiol 1997; 30: 141-148.

4 Sullivan AK, Holdright DR, Wright CA, et al. Chest pain in women: clinical, investigative, and prognostic features. BMJ 1994; 308: 883-886.

5 Kothawade K, Bairey Merz CN. Microvascular coronary dysfunction in women: pathophysiology, diagnosis, and management. Curr Probl Cardiol 2011; 36: 291-318.

6 Shaw LJ, Bugiardini R, Merz CN. Women and ischemic heart disease: evolving knowledge. J Am Coll Cardiol 2009; 54: 1561-1575.

7 Canto JG, Goldberg RJ, Hand MM, et al. Symptom presentation of women with acute coronary syndromes: myth vs reality. Arch Intern Med 2007; 167: 2405-2413.

8 Bybee KA, Kara T, Prasad A, et al. Systematic review: transient left ventricular apical ballooning: a syndrome that mimics ST-segment elevation myocardial infarction. Ann Intern Med 2004; 141: 858-865.

9 Motiwala SR, Sarma A, Januzzi JL, O'Donoghue ML. Biomarkers in ACS and heart failure: should men and women be interpreted differently? Clin Chem 2014; 60: 35-43.

10 Balmelli C, Meune C, Twerenbold R, et al. Comparison of the performances of cardiac troponins, including sensitive assays, and copeptin in the diagnostic of acute myocardial infarction and long-term prognosis between women and men. Am Heart J 2013; 166: 30-37.

11 Malacrida R, Genoni M, Maggioni AP, et al. A comparison of the early outcome of acute myocardial infarction in women and men. The Third International Study of Infarct Survival Collaborative Group. N Engl J Med 1998; 338: 8-14.

12 Rogers WJ, Frederick PD, Stoehr E, et al. Trends in presenting characteristics and hospital mortality among patients with ST elevation and non-ST elevation myocardial infarction in the National Registry of Myocardial Infarction from 1990 to 2006. Am Heart J 2008; 156: 1026-1034.

13 Vaccarino V, Parsons L, Every NR, et al. Sex-based differences in early mortality after myocardial infarction. National Registry of Myocardial Infarction 2 Participants. N Engl J Med 1999; 341: 217-225.

14 Rosengren A, Spetz CL, Köster M, et al. Sex differences in survival after myocardial infarction in Sweden; data from the Swedish National Acute Myocardial Infarction Register. Eur Heart J 2001; 22: 314-322.

15 O'Donoghue M, Boden WE, Braunwald E, et al. Early invasive vs conservative treatment strategies in women and men with unstable angina and nonST-segment elevation myocardial infarction: a meta-analysis. JAMA 2008; 300: 71-80.

16 Swahn E, Alfredsson J, Afzal R, et al. Early invasive compared with a selective invasive strategy in women with non-ST-elevation acute coronary syndromes: a substudy of the OASIS 5 trial and a meta-analysis of previous randomized trials. Eur Heart J 2012; 33: 51-60.

17 Blomkalns AL, Chen AY, Hochman JS, et al. Gender disparities in the diagnosis and treatment of non-ST-segment elevation acute coronary syndromes: large-scale observations from the CRUSADE (Can Rapid Risk Stratification of Unstable Angina Patients Suppress Adverse Outcomes With Early Implementation of the American College of Cardiology/American Heart Association Guidelines) National Quality Improvement Initiative. J Am Coll Cardiol 2005; 45: 832-837. 
18 Bradshaw PJ, Thompson PL. Sex in the CCU: women with non-ST-segment elevation acute coronary syndrome may do no worse despite less intervention. Heart 2007; 93: 1327-1328.

19 Berger JS, Bairey-Merz CN, Redberg RF, Douglas PS; DCRI Think Tank. Improving the quality of care for women with cardiovascular disease: report of a DCRI Think Tank, March 8 to 9, 2007. Am Heart J 2008; 156: 816-825.

20 Antithrombotic Trialists' (ATT) Collaboration, Baigent C, Blackwell L, et al. Aspirin in the primary and secondary prevention of vascular disease: collaborative meta-analysis of individual participant data from randomised trials. Lancet 2009; 373: 1849-1860.

21 Berger JS, Bhatt DL, Cannon CP, et al. The relative efficacy and safety of clopidogrel in women and men: a sex-specific collaborative meta-analysis. J Am Coll Cardiol 2009; 54: 1935-1945.

22 Husted S, James SK, Bach RG, et al. The efficacy of ticagrelor is maintained in women with acute coronary syndromes participating in the prospective, randomized, PLATelet inhibition and patient Outcomes (PLATO) trial. Eur Heart J 2014; 35: 1541-1550. doi: 10.1093/eurheartj/ehu075.

23 Hague W, Forder P, Simes J, et al; LIPID Investigators. Effect of pravastatin on cardiovascular events and mortality in 1516 women with coronary heart disease: results from the Long-Term Intervention with Pravastatin in Ischemic Disease (LIPID) study. Am Heart J 2003; 145: 643-651.

24 Gutierrez J, Ramirez G, Rundek T, Sacco RL. Statin therapy in the prevention of recurrent cardiovascular events: a sex-based meta-analysis. Arch Intern Med 2012; 172: 909-919.

25 Pilote L, Dasgupta K, Guru V, et al. A comprehensive view of sex-specific issues related to cardiovascular disease. CMAJ 2007; 176: SI-S44.

26 Cho L, Mukherjee D. Hormone replacement therapy and secondary cardiovascular prevention: a meta-analysis of randomized trials. Cardiology 2005; 104: 143-147.

27 Alexander KP, Roe MT, Chen AY, et al; CRUSADE Investigators. Evolution in cardiovascular care for elderly patients with non-ST-segment elevation acute coronary syndromes: results from the CRUSADE National Quality Improvement Initiative. J Am Coll Cardiol 2005; 46: 1479-1487.

28 Morrow DA, Antman EM, Charlesworth A, et al. TIMI risk score for STelevation myocardial infarction: a convenient, bedside, clinical score for risk assessment at presentation: an intravenous nPA for treatment of infarcting myocardium early II trial substudy. Circulation 2000; 102: 2031-2037.

29 Granger CB, Goldberg RJ, Dabbous O, et al. Predictors of hospital mortality in the Global Registry of Acute Coronary Events. Arch Intern Med 2003; 163 : 2345-2353.

30 Avezum A, Makdisse M, Spencer F, et al. Impact of age on management and outcome of acute coronary syndrome: observations from the Global Registry of Acute Coronary Events (GRACE). Am Heart J 2005; 149: 67-73.

31 Marschner IC, Colquhoun D, Simes RJ, et al; Long-Term Intervention with Pravastatin in Ischemic Disease (LIPID) Study. Long-term risk stratification for survivors of acute coronary syndromes. Results from the Long-term Intervention with Pravastatin in Ischemic Disease (LIPID) Study. LIPID Study Investigators. J Am Coll Cardiol 2001; 38: 56-63.

32 Brieger D, Eagle KA, Goodman SG, et al; GRACE Investigators. Acute coronary syndromes without chest pain, an underdiagnosed and undertreated high-risk group: insights from the Global Registry of Acute Coronary Events. Chest 2004; 126: 461-469.

33 Dornbrook-Lavender KA, Roth MT, Pieper JA. Secondary prevention of coronary heart disease in the elderly. Ann Pharmacother 2003; 37: 1867-1876.

34 Collaborative overview of randomized trials of antiplatelet therapy - I: prevention of death, myocardial infarction, and stroke by prolonged antiplatelet therapy in various categories of patients. Antiplatelet Trialists' Collaboration. BMJ 1994; 308: 81-106.

35 Yusuf S, Zhao F, Mehta SR, et al; Clopidogrel in Unstable Angina to Prevent Recurrent Events Trial Investigators. Effects of clopidogrel in addition to aspirin in patients with acute coronary syndromes without ST-segment elevation. NEngl J Med 2001; 345: 494-502.

36 Mehta SR, Yusuf S, Peters RJ, et al; Clopidogrel in Unstable Angina to Prevent Recurrent Events (CURE) Trial Investigators. Effects of pretreatment with clopidogrel and aspirin followed by long-term therapy in patients undergoing percutaneous coronary intervention: the PCI-CURE study Lancet 2001; 358: 527-533.

37 Budaj A, Yusuf S, Mehta SR, et al; Clopidogrel in Unstable Angina to Prevent Recurrent Events (CURE) Trial Investigators. Benefit of clopidogrel in patients with acute coronary syndromes without ST-segment elevation in various risk groups. Circulation 2002; 106: 1622-1626.

38 Wiviott SD, Braunwald E, McCabe CH, et al; TRITON-TIMI 38 Investigators. Prasugrel versus clopidogrel in patients with acute coronary syndromes. NEngl J Med 2007; 357: 2001-2015.

39 Husted S, James S, Becker RC, et al; PLATO study group. Ticagrelor versus clopidogrel in elderly patients with acute coronary syndromes: a substudy from the prospective randomized PLATelet inhibition and patient Outcomes (PLATO) trial. Circ Cardiovasc Qual Outcomes 2012; 5: 680-688.

40 LaRosa JC, He J, Vupputuri S. Effect of statins on risk of coronary disease: a meta-analysis of randomized controlled trials. JAMA 1999; 282: 2340-2346.
41 Shepherd J, Blauw GJ, Murphy MB, et al; PROSPER Study Group. Pravastatin in elderly individuals at risk of vascular disease (PROSPER): a randomised controlled trial. Lancet 2002; 360: 1623-1630.

42 Heart Protection Study Collaborative Group. MRC/BHF Heart Protection Study of cholesterol lowering with simvastatin in 20,536 high-risk individuals: a randomised placebo-controlled trial. Lancet 2002; 360: 7-22.

43 Cholesterol Treatment Trialists' (CTT) Collaboration, Baigent C, Blackwell L, et al. Efficacy and safety of more intensive lowering of LDL cholesterol: a meta-analysis of data from 170,000 participants in 26 randomised trials. Lancet 2010; 376: 1670-1681.

44 Schwartz GG, Olsson AG, Ezekowitz MD, et al. Effects of atorvastatin on early recurrent ischemic events in acute coronary syndromes: the MIRACL study: a randomized controlled trial. JAMA 2001; 285: 1711-1718.

45 Cannon CP, Braunwald E, McCabe CH, et al; Pravastatin or Atorvastatin Evaluation and Infection Therapy-Thrombolysis in Myocardial Infarction 22 Investigators. Intensive versus moderate lipid lowering with statins after acute coronary syndromes. N Engl J Med 2004; 350: 1495-1504.

46 Hilmer SN, Gnjidic D. Statins in older adults. Aust Prescr 2013; 36: 79-82. http://www.australianprescriber.com/magazine/36/3/79/82 (accessed Apr 2014).

47 Swedko PJ, Clark HD, Paramsothy K, Akbari A. Serum creatinine is an inadequate screening test for renal failure in elderly patients. Arch Intern Med 2003; 163: 356-360.

48 Levey AS, Stevens LA, Schmid CH, et al. A new equation to estimate glomerular filtration rate. Ann Intern Med 2009; 150: 604-612.

49 Mehran R, Aymong ED, Nikolsky E, et al. A simple risk score for prediction of contrast-induced nephropathy after percutaneous coronary intervention: development and initial validation. J Am Coll Cardiol 2004; 44: 1393-1399.

50 Alexander KP, Chen AY, Roe MT, et al; CRUSADE Investigators. Excess dosing of antiplatelet and antithrombin agents in the treatment of non-STsegment elevation acute coronary syndromes. JAMA 2005; 294: 3108-3116.

51 Lopes RD, Alexander KP, Marcucci G, et al. Outcomes in elderly patients with acute coronary syndromes randomized to enoxaparin vs. unfractionated heparin: results from the SYNERGY trial. Eur Heart J 2008; 29: 1827-1833.

52 Lim W, Dentali F, Eikelboom JW, Crowther MA. Meta-analysis: lowmolecular-weight heparin and bleeding in patients with severe renal insufficiency. Ann Intern Med 2006; 144: 673-684.

53 Hoenig MR, Aroney CN, Scott IA. Early invasive versus conservative strategies for unstable angina and non-ST elevation myocardial infarction in the stent era. Cochrane Database Syst Rev 2010; (3): CD004815.

54 Bach RG, Cannon CP, Weintraub WS, et al. The effect of routine, early invasive management on outcome for elderly patients with non-STsegment elevation acute coronary syndromes. Ann Intern Med 2004; 141: 186-195.

55 Fox KA, Anderson FA Jr, Dabbous OH, et al; GRACE investigators. Intervention in acute coronary syndromes: do patients undergo intervention on the basis of their risk characteristics? The Global Registry of Acute Coronary Events (GRACE). Heart 2007; 93: 177-182.

56 Malkin CJ, Prakash R, Chew DP. The impact of increased age on outcome from a strategy of early invasive management and revascularisation in patients with acute coronary syndromes: retrospective analysis study from the ACACIA registry. BMJ Open 2012; 2: e000540.

57 Blanton C, Thompson PL. Role of coronary interventional procedures in improved postinfarction survival in the 1990s. Am J Cardiol 2001; 87 832-837.

58 Rao SV, Eikelboom JA, Granger CB, et al. Bleeding and blood transfusion issues in patients with non-ST-segment elevation acute coronary syndromes. Eur Heart J 2007; 28: 1193-1204.

59 Donahoe SM, Stewart GC, McCabe CH, et al. Diabetes and mortality following acute coronary syndromes. JAMA 2007; 298: 765-775.

$60 \mathrm{Kip} \mathrm{KE}$, Faxon DP, Detre KM, et al. Coronary angioplasty in diabetic patients. The National Heart, Lung, and Blood Institute Percutaneous Transluminal Coronary Angioplasty Registry. Circulation 1996; 94: 1818-1825.

61 Silva JA, Escobar A, Collins TJ, et al. Unstable angina. A comparison of angioscopic findings between diabetic and nondiabetic patients. Circulation 1995; 92: 1731-1736.

62 Schilling JD, Mann DL. Diabetic cardiomyopathy: bench to bedside. Heart Fail Clin 2012: 8: 619-631.

63 Fang ZY, Schull-Meade R, Leano R, et al. Screening for heart disease in diabetic subjects. Am Heart J 2005; 149: 349-354.

64 Capes SE, Hunt D, Malmberg K, Gerstein HC. Stress hyperglycaemia and increased risk of death after myocardial infarction in patients with and without diabetes: a systematic overview. Lancet 2000; 355: 773-778.

65 Nathan DM, Cleary PA, Backlund JY, et al. Intensive diabetes treatment and cardiovascular disease in patients with type I diabetes. NEngl J Med 2005; 353: 2643-2653.

66 Holman RR, Paul SK, Bethel MA, et al. 10-year follow-up of intensive glucose control in type 2 diabetes. N Engl J Med 2008; 359: 1577-1589. 
67 Malmberg K, Rydén L, Efendic S, et al. Randomized trial of insulin-glucose infusion followed by subcutaneous insulin treatment in diabetic patients with acute myocardial infarction (DIGAMI study): effects on mortality at 1 year. J Am Coll Cardiol 1995; 26: 57-65.

68 Malmberg K, Rydén L, Wedel $\mathrm{H}$, et al. Intense metabolic control by means of insulin in patients with diabetes mellitus and acute myocardial infarction (DIGAMI 2): effects on mortality and morbidity. Eur Heart J 2005; 26: 650-661.

69 Mehta SR, Yusuf S, Díaz R, et al. Effect of glucose-insulin-potassium infusion on mortality in patients with acute ST-segment elevation myocardial infarction: the CREATE-ECLA randomized controlled trial. JAMA 2005; 293: 437-446.

70 Yusuf S, Mehta SR, Chrolavicius S, et al; OASIS-6 Trial Group. Effects of fondaparinux on mortality and reinfarction in patients with acute STsegment elevation myocardial infarction: the OASIS- 6 randomized trial. JAMA 2006; 295: 1519-1530.

71 Selker HP, Beshansky JR, Sheehan PR, et al. Out-of-hospital administration of intravenous glucose-insulin-potassium in patients with suspected acute coronary syndromes: the IMMEDIATE randomized controlled trial. JAMA 2012; 307: 1925-1933.

72 Selker HP, Udelson JE, Massaro JM, et al. One-year outcomes of out-ofhospital administration of intravenous glucose, insulin, and potassium (GIK) in patients with suspected acute coronary syndromes (from the IMMEDIATE [Immediate Myocardial Metabolic Enhancement During Initial Assessment and Treatment in Emergency Care] Trial). Am J Cardiol 2014; 113: 1599-1605.

73 NICE-SUGAR Study Investigators, Finfer S, Liu B, et al. Hypoglycemia and risk of death in critically ill patients. NEngl J Med 2012; 367: 1108-1118.

74 Rydén L, Grant PJ, Anker SD, et al. ESC Guidelines on diabetes, prediabetes, and cardiovascular diseases developed in collaboration with the EASD. Eur Heart J 2013; 34: 3035-3087.

75 Wiviott SD, Braunwald E, Angiolillo DJ, et al; TRITON-TIMI 38 Investigators. Greater clinical benefit of more intensive oral antiplatelet therapy with prasugrel in patients with diabetes mellitus in the trial to assess improvement in therapeutic outcomes by optimizing platelet inhibition with prasugrel - Thrombolysis in Myocardial Infarction 38. Circulation 2008; 118: 1626-1636.

76 James S, Angiolillo DJ, Cornel JH, et al. Ticagrelor vs. clopidogrel in patients with acute coronary syndromes and diabetes: a substudy from the PLATelet inhibition and patient Outcomes (PLATO) trial. Eur Heart J 2010; 31: 3006-2016.

77 De Luca G, Navarese E, Marino P. Risk profile and benefits from Gp IlbIlla inhibitors among patients with ST-segment elevation myocardial infarction treated with primary angioplasty: a meta-regression analysis of randomized trials. Eur Heart J 2009; 30: 2705-2713.

78 Cholesterol Treatment Trialists' (CTT) Collaborators, Kearney PM, Blackwell L, et al. Efficacy of cholesterol-lowering therapy in 18,686 people with diabetes in 14 randomised trials of statins: a meta-analysis. Lancet 2008; 371: 117-125.

79 Cannon CP, Steinberg BA, Murphy SA, et al. Meta-analysis of cardiovascular outcomes trials comparing intensive versus moderate statin therapy. J Am Coll Cardiol 2006; 48: 438-445.

80 Ahmed S, Cannon CP, Murphy SA, Braunwald E. Acute coronary syndromes and diabetes: is intensive lipid lowering beneficial? Results of the PROVE IT-TIMI 22 trial. Eur Heart J 2006; 27: 2323-2329.

81 Keech A, Simes RJ, Barter P, et al. Effects of long-term fenofibrate therapy on cardiovascular events in 9795 people with type 2 diabetes mellitus (the FIELD study): randomised controlled trial. Lancet 2005; 366: 1849-1861.

82 Jun M, Foote C, LV J, et al. Effects of fibrates on cardiovascular outcomes: a systematic review and meta-analysis. Lancet 2010; 375: 1875-1884.

83 O'Donoghue ML, Vaidya A, Afsal R, et al. An invasive or conservative strategy in patients with diabetes mellitus and non-ST-segment elevation acute coronary syndromes: a collaborative meta-analysis of randomized trials. J Am Coll Cardiol 2012; 60: 106-111.

84 Farkouh ME, Domanski, M, Sleeper L, et al. Strategies for multivessel revascularization in patients with diabetes. NEngl J Med 2012; 367: 2375-2384.

85 Verma S, Farkouh ME, Yanagawa B, et al. Comparison of coronary artery bypass surgery and percutaneous coronary intervention in patients with diabetes: a meta-analysis of randomised controlled trials. Lancet Diabetes Endocrinol 2013; 1: 317-328.

86 Anderson JL, Adams CD, Antman EM, et al. 2012 ACCF/AHA focused update incorporated into the ACCF/AHA 2007 guidelines for the management of patients with unstable angina/non-ST-elevation myocardial infarction: a report of the American College of Cardiology Foundation/American Heart Association Task Force on Practice Guidelines. Circulation 2013; 127 : e663-e828.

87 O'Gara PT, Kushner FG, Ascheim DD, et al. 2013 ACCF/AHA guideline for the management of ST-elevation myocardial infarction: a report of the American College of Cardiology Foundation/American Heart Association Task Force on Practice Guidelines. J Am Coll Cardiol 2013; 61: e78- el40.

88 Australian Institute of Health and Welfare. Cardiovascular disease by populations of interest. http://www.aihw.gov.au/cardiovascular-health/ populations-of-interest (accessed Apr 2014).

89 Thompson PL, Bradshaw PJ, Veroni M, Wilkes ET. Cardiovascular risk among urban Aboriginal people. Med J Aust 2003; 179: 143-146.

90 Bradshaw PJ, Wilkes ET, Thompson PL. Determinants of carotid intima-medial thickness in an urban Australian Aboriginal population. Atherosclerosis 2007; 192: 218-223.

91 Mathur S, Moon L, Leigh S. Aboriginal and Torres Strait Islander people with coronary heart disease: further perspectives on health status and treatment. Canberra: Australian Institute of Health and Welfare, 2006 (AlHW Cat. No. CVD 33; Cardiovascular Disease Series No. 25.) http:// www.aihw.gov.au/publication-detail/?id=6442467898 (accessed Oct 2014).

92 Wang Z, Hoy WE. Is the Framingham coronary heart disease absolute risk function applicable to Aboriginal people? Med J Aust 2005; 182: 66-69.

93 Bradshaw PJ, Alfonso HS, Finn JC, et al. Coronary heart disease events in Aboriginal Australians: incidence in an urban population. Med J Aust 2009; 190: 583-586

94 Bradshaw PJ, Alfonso HS, Finn J, et al. A comparison of coronary heart disease event rates among urban Australian Aboriginal people and a matched non-Aboriginal population. J Epidemiol Community Health 2011; 65: 315-319.

95 Katzenellenbogen JM, Sanfilippo FM, Hobbs MS, et al. Incidence of and case fatality following acute myocardial infarction in Aboriginal and nonAboriginal Western Australians (2000-2004): a linked data study. Heart Lung Circ 2010; 19: 717-725.

96 Katzenellenbogen JM, Sanfilippo FM, Hobbs MS, et al. Aboriginal to nonAboriginal differentials in 2-year outcomes following non-fatal first-ever acute Ml persist after adjustment for comorbidity. Eur J Prev Cardiol 2012; 19: 983-990.

97 Davidson PM, Maclsaac A, Cameron J, et al. Problems, solutions and actions: addressing barriers in acute hospital care for Indigenous Australians and New Zealanders. Heart Lung Circ 2012; 21: 639-643.

98 Bradshaw PJ, Alfonso HS, Finn J, et al. The use of coronary revascularisation procedures in urban Australian Aboriginals and a matched general population coronary procedures in Aboriginals. Heart Lung Circ 2010; 19: 247-250.

99 Gausia K, Katzenellenbogen JM, Sanfilippo FM, et al. Evidence-based prescribing of drugs for secondary prevention of acute coronary syndrome in Aboriginal and non-Aboriginal patients admitted to Western Australian hospitals. Intern Med J 2014; 44: 353-361. 